УДК

\title{
ДИНАМИЧЕСКОЕ РАСПРЕДЕЛЕНИЕ РЕСУРСОВ В ОFDМ СИСТЕМЕ КОГНИТИВНОГО РАДИО С УЧЕТОМ КАЧЕСТВА ОБСЛУЖИВАНИЯ ПОЛЬЗОВАТЕЛЕЙ
}

\author{
КИШОР В. КРИШНАН ${ }^{1}$, САДЖИТХ РАДЖАН ${ }^{1}$, СИБАРАМ ХАРА ${ }^{2}$ \\ ${ }^{1}$ VIT университет, \\ Индия, Веллуру, 632014, Тамилнад \\ ${ }^{2}$ Галгошиаз Университет, \\ Индия, Нойда, Уттар-Прадеш
}

\begin{abstract}
Аннотация. Во многих современных радиосистемах полный спектр частот используется неэффективно. Эта проблема решается с помощью когнитивного радио. Когнитивное радио является беспроводной технологией с искусственным интеллектом, которая позволяет выделять нелицензированным пользователям каналы лицензированных пользователей, не влияя на лицензированных пользователей, тем самым улучшая эффективность использования спектра. В этой статье рассмотрена система когнитивного радио (КР) с использованием многопользовательского мультиплексирования с ортогональным частотным разделением (MU-OFDM). В обычной OFDM системе максимальная пропускная способность обеспечивается путем использования алгоритма создания избытка информации (water filling algorithm). Выполнена совместная оптимизация распределения мощности и поднесущих частот для OFDM системы КР при многопользовательском режиме работы. При этом использован модифицированный с помощью теории конвексной оптимизации алгоритм создания избытка информации. Применение этого алгоритма, обеспечило более высокую безошибочную пропускную способность при ограниченных общей и пиковой мощностях сигналов
\end{abstract}

Ключевые слова: OFDM; когнитивное радио; динамическое выделение ресурсов

\section{1. ВВЕДЕНИЕ}

Большинство беспроводных систем связи, использующих частоты ниже 6 ГГц, стали постоянно перегруженными при возрастающем количестве областей их практического применения. В соответствии с общепринятыми правилами регулирования некоторые каналы выделяются для особых пользователей (лицензированные пользователи), а остальные пользователи не имеют доступа к этим каналам. Таким образом, когда лицензированные пользователи не используют эти каналы, многие из спектральных каналов являются недоиспользованными. Это приводит к резкому снижению эффективности использования спектра [1].
Исследования, проведенные Федеральной комиссией по связи США FCC, позволили понять, что использование спектра лежит в диапазоне от 15 до 85\%. Для повышения эффективности использования спектра разработана новая концепция, которая носит название система когнитивного радио (cognitive radio). Система когнитивного радио (КР) является адаптивной интеллектуальной сетевой технологией, которая динамически обнаруживает доступные каналы в спектре и за счет них улучшает параметры передачи, что обеспечивает большее количество каналов связи, функционирующих одновременно при лучшей эффективности работы [2]. 